\title{
REFERENCES
}

Arriagada, A., Savage, M. C., Abraham, E. P., Heatley, N. G. \& Sharp, A. E. (1949). Brit. J. exp. Path. 30, 425.

Berridge, N. J., Newton, G. G. F. \& Abraham, E. P. (1952). Biochem. J. 52, 529.

Blackburn, S. \& Lowther, A. G. (1951). Biochem. J. 48, 126.

Brush, M. K., Boutwell, R. K., Barton, A. D. \& Heidelberger, C. (1951). Science, 113, 4.

Consden, R., Gordon, A. H., Martin, A. J. P., Rosenheim, O. \& Synge, R. L. M. (1945). Biochem. J. 39, 251.

Craig, L. C. \& Craig, D. (1950). In Technique of Organic Chemistry, vol. 3, ch. 4. Ed by Weissberger, A. New York: Interscience.

Craig, L. C., Gregory, J. D. \& Barry, G. T. (1949). J. clin. Invest. 28, 1014.

Craig, L. C., Hausmann, W., Ahrens, E. H. \& Harfenist, E. J. (1951). Analyt. Chem. 23, 1236.

Dent, C. E. (1948). Biochem. J. 43, 169.
Frick, G. (1952). Nature, Lond., 169, 758.

Heạtley, N. G. (1944). Biochem. J. 38, 61.

Jorpes, E. (1932). Biochem. J. 26, 1507.

Newton, G. G. F. \& Abraham, E. P. (1950). Biochem. J. 47, 257.

Newton, G. G. F. \& Abraham, E. P. (1952). Nature, Lond., $169,69$.

Newton, G. G. F. \& Abraham, E. P. (1953). Biochem. J. 53, 604.

Porter, R. R. \& Sanger, F. (1948). Biochem. J. 42, 287.

Sanger, F. (1945). Biochem. J. 39, 507.

Sharp, V. E., Arriagada, A., Newton, G. G. F. \& Abraham, E. P. (1949). Brit. J. exp. Path. 30, 444.

Smith, J. D. \& Markham, R. (1950). Biochem. J. 46, 509.

Steele, B. F., Sauberlich, H. E., Reynolds, M. S. \& Baumann, C. A. (1949). J. biol. Chem. 177, 533.

Stein, W. H. \& Moore, S. (1951). J. biol. Chem. 190, 103.

Woiwod, A. J. (1949). J. gen. Microbiol. 3, 312.

\section{Observations on the Nature of Bacitracin $A$}

\author{
By G. G. F. NEWTON AND E. P. ABRAHAM \\ Sir William Dunn School of Pathology, University of Oxford
}

(Received 11 August 1952)

Bacitracin $A$, the main active member of the bacitracin family of polypeptides, was obtained by counter-current distribution between solvents in amounts sufficient for some of its properties to be investigated in detail (Newton \& Abraham, 1953). Previous work with bacitracin (Sharp, Arriagada, Newton \& Abraham, 1949; Craig, Gregory \& Barry, 1949; Newton \& Abraham, 1950) indicated that the substance was a good deal less stable than would be expected if it consisted only of amino-acids joined by normal peptide linkages. The investigations described in this paper were designed largely to throw light on the nature of the more labile portions of the molecule of bacitracin $A$.

\section{RESULTS}

\section{Composition and molecular weight of bacitracin $\mathbf{A}$}

Barry, Gregory \& Craig (1948) reported the results of an analysis made by Moore \& Stein, on a starch column, of the amino-acids present in purified bacitracin. Using these results as a basis it was found that paper chromatograms of an acid hydrolysate of bacitracin $A$ appeared very similar to chromatograms of the following mixture of aminoacids in the molecular proportions shown (Newton \&
Abraham, 1953): cystine, 0.5 ; ornithine, 1 ; lysine, 1 ; histidine, 1; aspartic acid, 2; glutamic acid, 1; phenylalanine, 1 ; leucine, 1 ; isoleucine, 2.

The relative values obtained by Moore \& Stein for the amino-acids other than cystine and ornithine (which was not determined) are in agreement with the molecular proportions of the amino-acids in this mixture. The value suggested here for cystine is based on the sulphur content of bacitracin $A$ hydrochloride, which was found by elementary analysis to be $1.82 \%$.

Sharp et al. (1949) concluded from experiments with D-amino-acid oxidase that some of the aminoacids in crude bacitracin (ayfivin) had the D-configuration. Craig et al. (1949) isolated DL-phenylalanine, DL-aspartic acid and partially racemic $D$ isoleucine from purified bacitracin.

If the weights of the residues of the amino-acids shown above are combined, and if the weight of three molecules of hydrochloric acid is added, a figure of approximately 1500 is arrived at for the weight of the minimum stoicheiometric unit of bacitracin $A$ hydrochloride. The presence of only one atom of sulphur in the molecule is possible because, although cystine is finally obtained on hydrolysis, it is derived from a cysteine residue (see below). 
The amount of amide nitrogen liberated on hydrolysis, i.e. the amount of nitrogen liberated as ammonia by hydrolysis with $\mathrm{N}$-hydrochloric acid for $20 \mathrm{~min}$. or longer at $100^{\circ}$, and the spans of the titration curve (see below), also indicate that the minimum stoicheiometric unit is close to 1500 . The molecular weight may, of course, be a multiple of 1500. No evidence that this is so has been obtained in the present work, but the isolation of DL-phenylalanine from purified bacitracin by Craig et al. (1949) would suggest that more than one residue of this amino-acid is present in the molecule.* Anker, Johnson, Goldberg \& Meleney (1948) stated that bacitracin would diffuse through a nitrocellulose membrane which held back particles of molecular weight greater than 2000 .

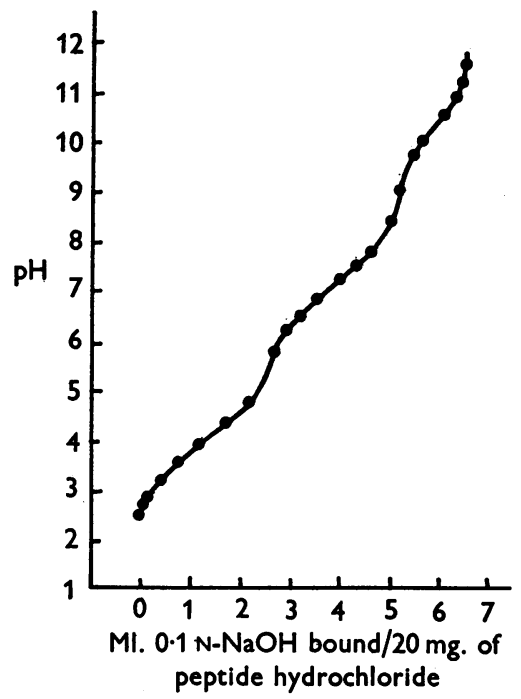

Fig. 1. Titration curve of bacitracin $A$.

\section{Acid and basic groups}

Titration curve. Fig. 1 shows a titration curve of bacitracin $A$. The peptide contains groups which ionize in three distinct ranges of hydrogen-ion concentration. The alkali bound in the $\mathrm{pH}$ range $2 \cdot 5-5 \cdot 5$ could be attributed to the presence of two carboxyl groups, that bound between $\mathrm{pH} 5.5$ and 8.5 to the presence of the glyoxaline ring of histidine, and of a free $\alpha$-amino group, and that bound between $\mathrm{pH} 8.5$ and 11.5 to either the $\delta$-amino group of ornithine or the $\epsilon$-amino group of lysine.

\section{Reaction with 1-fluoro-2:4-dinitrobenzene (FDNB)}

Bacitracin $A$ was treated with FDNB in sodium bicarbonate solution (Sanger, 1945). Hydrolysis of the dinitrophenyl-(DNP-) bacitracin was found to

* Since this paper was written Craig, Hausmann \& Weisiger ( $J$. biol. Chem. in the Press) have stated that pure bacitracin $A$ yields only D-phenylalanine on hydrolysis. yield substances which behaved on paper chromatograms like DNP-leucine or DNP-isoleucine, glyDNP-histidine and $\delta$-DNP-ornithine. The remaining amino-acids were not in the form of DNP derivatives. It therefore appears that the peptide contains a free $\alpha$-amino group belonging to a leucine or an isoleucine residue, a free $\mathrm{NH}$ in the glyoxaline ring of a histidine residue, and a free $\delta$-amino group belonging to ornithine. The $\epsilon$-amino group of lysine, however, is not free.

These results are in agreement with the conclusions drawn from the titration curve.

\section{Inactivation of bacitracin $\mathbf{A}$ by acid}

Liberation of a thiol group. At a concentration of $10 \mathrm{mg} . / \mathrm{ml}$. bacitracin $A$ showed no nitroprusside reaction in the absence or the presence of sodium cyanide. It therefore appeared to contain no free thiol group and no disulphide.

On hydrolysis for $20 \mathrm{~min}$. at $100^{\circ}$ with $0.5 \mathrm{~N}$ hydrochloric acid, the substance lost its antibacterial activity and showed a strong nitroprusside reaction at a concentration of $5 \mathrm{mg} . / \mathrm{ml}$. On the other hand, after hydrolysis for $16 \mathrm{hr}$. at $110^{\circ}$ with $6 \mathrm{~N}$-hydrochloric acid the nitroprusside reaction was negative unless sodium cyanide was present. This indicated that a thiol group was liberated on short hydrolysis, but was subsequently oxidized to a disulphide.

Attempts to estimate the amount of thiol liberated were made in two ways : first, by oxidation with iodine in phosphate buffer at pH 6.8 (Anson, 1941), and secondly, by oxidation with ferricyanide (Anson, 1940; Barron, 1951). The iodine absorbed was measured by adding a small excess of iodine and at once titrating back to the end point with sodium thiosulphate. The ferricyanide reduced was measured after reaction for $10 \mathrm{~min}$. at room temperature with the sample. In both cases the amount of oxidizing agent that reacted with the product of acid inactivation was significantly greater than the amount that would correspond to the oxidation of one thiol group, in the minimum stoicheiometric unit of bacitracin $A$, to a disulphide.

Table 1 shows the results obtained with bacitracin $A$, with the product formed after hydrolysis for $20 \mathrm{~min}$. at $100^{\circ}$ in $0.5 \mathrm{~N}$-hydrochloric acid, and with the product of complete acid hydrolysis, prepared by heating for $24 \mathrm{hr}$. at $110^{\circ}$ in $6 \mathrm{~N}$-hydrochloric acid. The values are related to $1500 \mathrm{~g}$. of bacitracin hydrochloride.

The ability to reduce ferricyanide under the conditions used increased rapidly during the first $10 \mathrm{~min}$. of the hydrolysis and reached a maximum within $20 \mathrm{~min}$. In $0.1 \mathrm{~N}$-hydrochloric acid at $100^{\circ}$ the initial rate at which reducing power increased was about one-fifth of the rate in $0.5 \mathrm{~N}$ acid. 
Table 1. Effect of treatment with acid on the potential thiol group in bacitracin $\mathbf{A}$

\begin{tabular}{|c|c|c|c|c|}
\hline \multirow[b]{2}{*}{ Substance } & \multirow{2}{*}{$\begin{array}{c}\text { Nitro- } \\
\text { prusside } \\
\text { test }\end{array}$} & \multirow{2}{*}{$\begin{array}{l}\text { Nitro- } \\
\text { prusside } \\
+\mathrm{NaCN}\end{array}$} & \multicolumn{2}{|c|}{$\begin{array}{l}\text { Oxidizing agent reacting } \\
\text { (equiv.) }\end{array}$} \\
\hline & & & Iodine & Ferricyanide \\
\hline Bacitracin $A$ & - & - & $0 \cdot 2$ & $0 \cdot 1$ \\
\hline Product of acid inactivation & +++ & +++ & $\mathbf{1 \cdot 6}$ & $1 \cdot 4$ \\
\hline Product of complete acid hydrolysis & - & ++ & - & $0 \cdot 1$ \\
\hline
\end{tabular}

The fact that the iodine values are somewhat greater than the ferricyanide values is understandable, because iodine is slowly absorbed by bacitracin $A$ before treatment with acid. For example, when $30 \mathrm{~min}$. were allowed before titrating back with thiosulphate, 0.8 equiv. of iodine was found to have been absorbed. The product showed no nitroprusside reaction in the presence of sodium cyanide and hence no disulphide appeared to have been formed. On the other hand, the product of inactivation by acid absorbed $2 \cdot 3$ equiv. of iodine in $30 \mathrm{~min}$. to form a substance which showed a positive nitroprusside reaction in the presence of cyanide. The iodine that is slowly absorbed by bacitracin $A$ presumably reacts with the histidine residue in the molecule. Histidine itself absorbed 0.8 equiv. of iodine in $30 \mathrm{~min}$. under the conditions used.

Since the amounts of iodine and ferricyanide that react rapidly with the product of acid inactivation are greater than would be expected for the oxidation of a single thiol group, the question arises whether a second reducing centre is formed when bacitracin $A$ is treated with acid. Evidence for the formation of a reducing centre other than a thiol group was obtained from the product of the oxidation of bacitracin in the presence of copper ions (see below).

Formation of S-DNP-cysteine from the product of acid inactivation. Further evidence that the thiol group of a cysteine residue is liberated on inactivation of bacitracin $A$ with acid was obtained by the use of FDNB. A sample of bacitracin $A$ was heated at $100^{\circ}$ for $30 \mathrm{~min}$. in $\mathrm{N}$-hydrochloric acid and allowed to react with an excess of FDNB in sodium bicarbonate solution (Sanger, 1945). After hydrolysis of the DNP-bacitracin $A$, two-dimensional paper chromatography revealed that cystine, as well as ornithine and histidine, was absent from its usual place on the chromatogram when the latter was developed with ninhydrin.

Ionophoresis on paper saturated with $0.02 \mathrm{M}$ borate buffer, pH $8 \cdot 8$, showed that the hydrolysate contained a DNP-amino-acid which moved towards the anode at the same rate as $S$-DNP-cysteine.

Liberation of ammonia. Treatment of bacitracin $A$ for $20 \mathrm{~min}$. with $\mathrm{N}$-hydrochloric acid caused the formation of 1 equiv. of volatile base as well as the liberation of a thiol group. The volatile base, which was estimated in Conway units (Conway, 1935), is provisionally assumed to be ammonia resulting from the hydrolysis of an amide group.

No carbon dioxide was liberated during the inactivation of bacitracin $A$ with acid.

Titration of the product of acid inactivation. Fig. 2 shows a titration curve of the product of inactivation by acid, side by side with the titration curve of bacitracin $A$. Acid inactivation has resulted in the formation of one group titrating in the $\mathrm{pH}$ range 2.5-5.5 and two groups titrating in the $\mathrm{pH}$ range

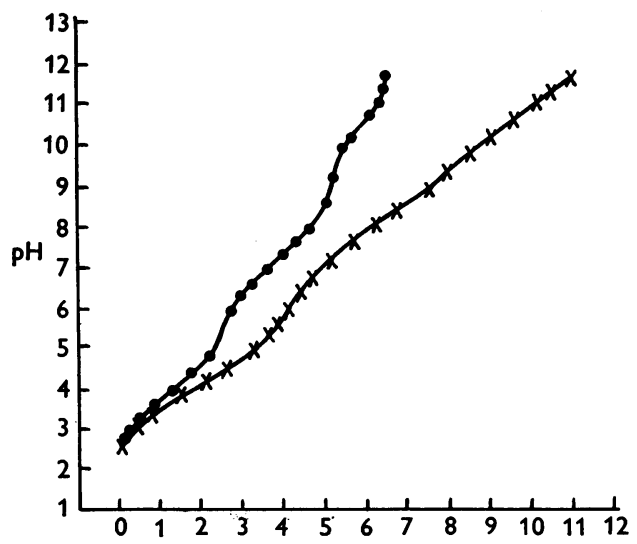

MI. $0.1 \mathrm{~N}-\mathrm{NaOH}$ bound $/ 20 \mathrm{mg}$. of peptide hydrochloride

Fig. 2. Titration curves of bacitracin $A$ and of bacitracin $A$ after treatment with $0.5 \mathrm{~N}-\mathrm{HCl}$. $-O$, bacitracin $A$; $\times-\times$, bacitracin $A$ after treatment with $0.5 \mathrm{~N}-\mathrm{HCl}$.

$5 \cdot 5-11 \cdot 5$. The first group could be a carboxyl group formed on hydrolysis of an amide. One of the latter two groups could be ammonia formed from an amide, while the other could be a free thiol group. Since the formation of these three groups is sufficient to account for the whole of the curve, no peptide bonds appear to be broken during the inactivation.

Ultraviolet absorption spectrum. Curve $B$ in Fig. 3 shows the ultraviolet absorption spectrum of the product of acid inactivation. The maximum present at $252 \mathrm{~m} \mu .\left(E_{1}^{1 \%} \mathrm{~cm}=20\right)$ in the absorption spectrum of bacitracin $A$ (curve $A$ ) has almost disappeared and the absorption in this range is similar to that of the mixture of amino-acids formed on complete hydrolysis (curve $C$ ). 
Precipitation with mercuric chloride. An attempt was made to fractionate the product of acid inactivation by precipitating the substance containing a free thiol group as a mercaptide. However, the material recovered from the precipitate and from the supernatant solution appeared to have the same amino-acid composition. After acid hydrolysis these materials showed chromatograms which were not distinguishable when developed with butanolacetic acid (Woiwod, 1949).

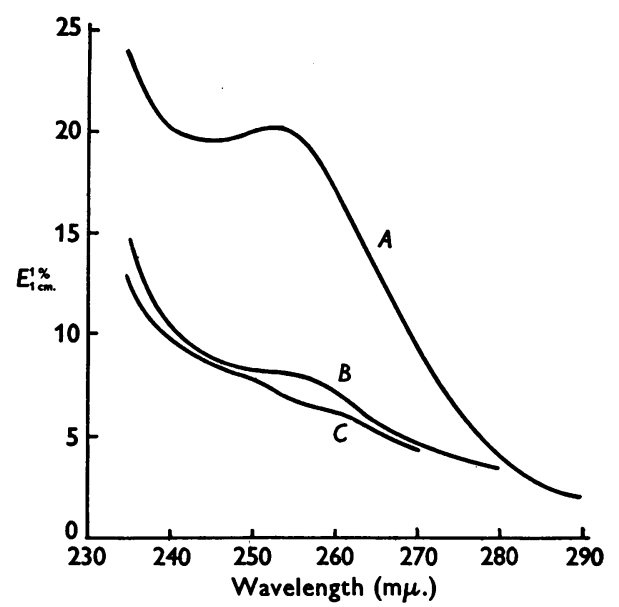

Fig. 3. Ultraviolet absorption spectra of bacitracin $A$ (curve $A$ ), of bacitracin $A$ after treatment with $0.5 \mathrm{~N}-\mathrm{HCl}$ (curve $B$ ), and of bacitracin $A$ after complete hydrolysis with $6 \mathrm{~N}-\mathrm{HCl}$ (curve $C$ ).

\section{Inactivation of bacitracin A by alkali}

A sample of bacitracin $A$ (37 units/mg.) was kept at $37^{\circ}$ for $2 \mathrm{hr}$. in $0 \cdot 1 \mathrm{~N}$-sodium hydroxide and the $\mathrm{pH}$ of the solution was then adjusted to $4 \cdot 0$. The antibacterial activity of the product was less than 0.2 unit/mg.

Measurement of volatile base in Conway units indicated that 1 equiv. of ammonia had been liberated during the treatment with alkali. No further volatile base was formed on subsequent hydrolysis with acid. Hence, acid and alkaline hydrolysis appear to liberate ammonia from the same group (presumably an amide group) in the peptide.

The product formed by the treatment with alkali showed a negative nitroprusside reaction. After subsequent treatment with $0.5 \mathrm{~N}$-hydrochloric acid for $20 \mathrm{~min}$. at $100^{\circ}$, however, it showed a strong nitroprusside reaction and reduced 1.4 equiv. of ferricyanide. Hence, during the inactivation of bacitracin $A$ by alkali it appeared that one amide group was hydrolysed but that the sulphur of the potential thiol group was unaffected. Relatively little change in the ultraviolet absorption spectrum of bacitracin $A$ occurred during the reaction, the value for $E_{1-\mathrm{cm}}^{1 ! \%}$ at $252 \mathrm{~m} \mu$. falling from 20 to 18 .

\section{Oxidation of bacitracin A by molecular oxygen in the presence of $\mathrm{Cu}^{++}$}

Sharp et al. (1949) found that bacitracin was rapidly inactivated in aqueous solution at $\mathrm{pH} 8$ in the presence of small amounts of a cupric salt. This inactivation is associated with an uptake of molecular oxygen, which results in the oxidation of the sulphur atom in the molecule and the liberation of ammonia.

Fig. 4 shows the uptake of oxygen when an aqueous solution of $16.6 \mathrm{mg}$. of bacitracin $A$

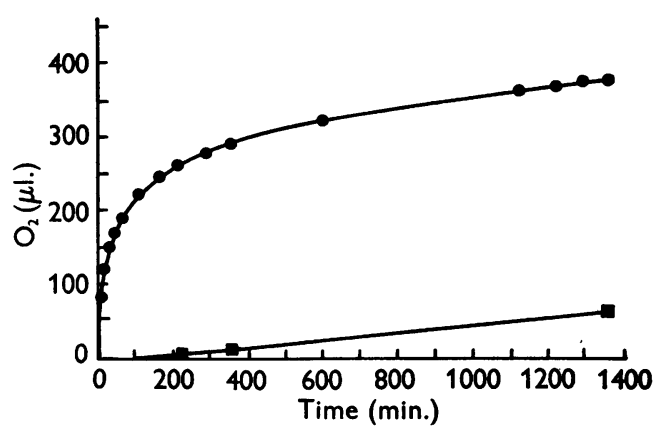

Fig. 4. Uptake of oxygen by bacitracin $A$ in the presence and absence of copper ions. $-\longrightarrow$, with $\mathrm{Cu}^{2+} ; \square-\square$, without $\mathrm{Cu}^{2+}$.

hydrochloride, adjusted to an initial $\mathrm{pH}$ of 8.1 and containing $1 \mathrm{~g}$. atom $\mathrm{Cu}^{2+} / 1500 \mathrm{~g}$. of peptide hydrochloride, was shaken at $37^{\circ}$ in air in a Warburg apparatus. The copper was added in the form of freshly precipitated cupric hydroxide. The initial reaction was rapid. Half an atom of oxygen (corresponding to the oxidation of one thiol group to a disulphide) was absorbed in about $10 \mathrm{~min}$. After two atoms of oxygen had been absorbed the reaction proceeded much more slowly. After $23 \mathrm{hr}$., when three atoms of oxygen had been absorbed, the reaction was stopped.

When different amounts of $\mathrm{Cu}^{2+}$ were used, varying from $0 \cdot 1$ to $1 \cdot 0 \mathrm{~g}$. atom $/ 1500 \mathrm{~g}$. of bacitracin $A$ hydrochloride, the initial rate of reaction was approximately proportional to the amount of copper present. Very slow absorption of oxygen also occurred at $\mathrm{pH} 8$ in the absence of added copper (Fig. 4).

In a further experiment, samples of partially purified bacitracin (containing about $60 \%$ bacitracin $A$ ) were allowed to absorb varying amounts of oxygen in the presence of $1 \mathrm{~g}$. atom $\mathrm{Cu}^{2+} / 1500 \mathrm{~g}$. of peptide. The $\mathrm{pH}$ first rose rapidly from $8 \cdot 4$ to $9 \cdot 0$ at the beginning of the reaction, and finally fell to $\mathbf{7 \cdot 7}$ 
Table 2. Oxidation of bacitracin by gaseous oxygen in a solution containing copper ions. The table shows the oxidation of the potential thiol group and the liberation of ammonia

$$
\begin{gathered}
\text { Oxygen } \\
\text { absorbed/1500 g. } \\
\text { peptide } \\
\text { hydrochloride } \\
\text { (g. atoms) }
\end{gathered}
$$

0
0.5
1.0
2.0

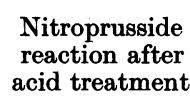

$+++$

$+$

$-$

$$
\begin{aligned}
& \text { Nitroprusside } \\
& \text { reaction after } \\
& \text { acid treatment } \\
& +\mathrm{NaCN} \\
& ++++ \\
& ++ \\
& ++
\end{aligned}
$$

$\begin{array}{cc}\begin{array}{c}\text { Ferricyanide } \\ \text { reduced after } \\ \text { acid treatment } \\ \text { (equiv.) }\end{array} & \begin{array}{c}\text { Free ammonia } \\ \text { liberated } \\ \text { (equiv.) }\end{array} \\ 1.2 & 0 \\ 0.7 & - \\ 0.6 & 0.7 \\ 0.6 & 1 \cdot 1\end{array}$

during the course of the oxidation. The rise in $\mathrm{pH}$ was evidently due to the liberation of hydroxyl ions on the formation of a copper complex of bacitracin. Copper was removed from the mixtures by shaking them with a solution of 8-hydroxyquinoline in chloroform. The free ammonia in samples of the products was determined in Conway units. Other samples were heated at $100^{\circ}$ in $0.5 \mathrm{~N}$-hydrochloric acid for $20 \mathrm{~min}$. and their ability to give a nitroprusside reaction and to reduce ferricyanide was then tested. The results of these experiments are shown in Table 2. The figures are related to $1500 \mathrm{~g}$. of partially purified bacitracin hydrochloride. Before acid hydrolysis none of the samples reduced more than $0 \cdot 1$ equiv. of ferricyanide.

It appears that in the first phase of rapid oxygen uptake by bacitracin $A$ there is an oxidation of a potential thiol group to a disulphide and the oxidative formation of a molecule of ammonia. The subsequent phase, in which oxygen is absorbed much more slowly, involves the further oxidation of the disulphide. A sample of bacitracin $A$ which had absorbed three atoms of oxygen was heated at $110^{\circ}$ for $24 \mathrm{hr}$. in $6 \mathrm{~N}$-hydrochloric acid and the hydrolysate chromatographed on paper in two dimensions. The cystine spot obtained from hydrolysates of bacitracin $A$ was absent, and was replaced by a spot in the same position as that occupied by cysteic acid.

Table 2 shows that oxidized samples of bacitracin reduced ferricyanide after treatment with acid, although they no longer liberated a thiol group. Nothing is known of the reducing centre concerned in this reaction.

The origin of the ammonia formed during the oxidation has also not yet been established. The product contained the same amount of amide $\mathrm{N}$ and the same amount of histidine (determined colorimetrically by the method of Jorpes, 1932) as bacitracin $A$.

\section{The copper complex of bacitracin}

Fig. 5 shows titration curves of bacitracin $A$ alone and of bacitracin $A$ in the presence of $\mathrm{Cu}^{2+}$ (1 g. atom/1500 g. of peptide hydrochloride). It is evident that the groups in bacitracin which normally titrate between $\mathrm{pH} 5.5$ and 8.5 form copper complexes which are only decomposed by hydrogen ions at considerably lower $\mathrm{pH}$ values. In the titration curve the combination of the copper complexes and of the carboxyl ions with hydrogen ions therefore occurs in the same range. A copper complex is presumably an intermediary in the oxidation of bacitracin.

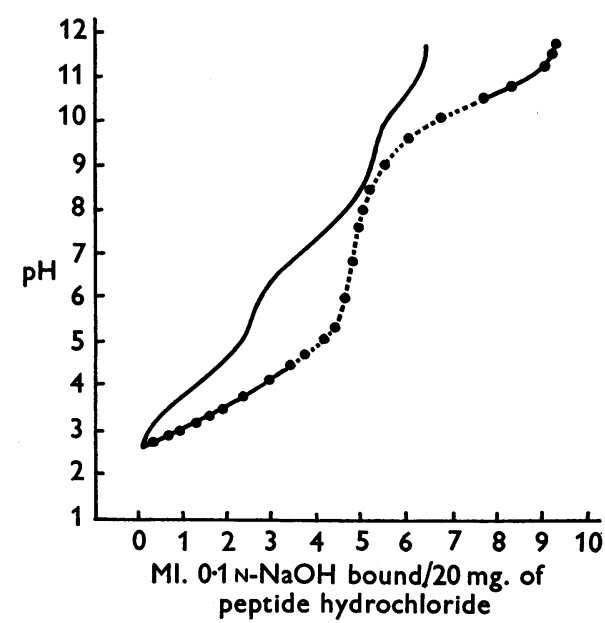

Fig. 5. Titration curves of bacitracin $A$ and of bacitracin $A$ in the presence of copper ions. - bacitracin $A$; - , bacitracin $A$ plus $\mathrm{Cu}^{2+}$. The broken part of the curve indicates that a precipitate formed.

When the $\mathrm{pH}$ is raised above 9.5 there is considerably greater buffering in the presence of $\mathrm{Cu}^{2+}$ than in its absence, two additional hydroxyl ions apparently being absorbed (cf. Dobbie, Kermack \& Lees, 1951).

These changes are reflected in the colour and solubility of the material. In the presence of $\mathrm{Cu}^{2+}$ the solution is pale yellow at $\mathrm{pH} \mathbf{2 \cdot 5}$, but becomes increasingly green above $\mathrm{pH} \mathrm{3.0}$ as complexformation begins. At $\mathrm{pH} 4 \cdot 7$ the complex begins to precipitate. Above $\mathrm{pH} \mathrm{10.5}$ a further change becomes evident, the precipitate dissolving to form a clear yellow solution. It is of interest that Sharp et al. (1949) found that bacitracin was inactivated more rapidly at $\mathrm{pH} 8$ than at $\mathrm{pH} 10.5$ in the presence of $\mathrm{Cu}^{2+}$. 


\section{Oxidation of bacitracin with bromine water}

Bacitracin $A$ is oxidized by bromine water with the loss of antibacterial activity. An excess of bromine water was added to an aqueous solution of bacitracin $A$ (final concentration $5 \mathrm{mg} . / \mathrm{ml}$.), when an orange-coloured precipitate formed. After $10 \mathrm{~min}$. at room temperature the amount of bromine remaining was determined by the addition of acidified potassium iodide solution and titration back with sodium thiosulphate. Under these conditions 10 equiv. of bromine were found to be absorbed per $1500 \mathrm{~g}$. of bacitracin $A$ hydrochloride.

In a second experiment the excess of bromine was removed from the solution by a current of air, when the orange-coloured precipitate disappeared and the solution became colourless and nearly clear. This behaviour suggested that an $N$-bromo compound or a molecular compound with bromine was formed, which dissociated as the free bromine was removed. The resulting solution contained $\mathbf{0 . 8}$ equiv. of free ammonia, but the amide nitrogen was still intact. The solution showed no nitroprusside reaction after treatment with $0.5 \mathrm{~N}$-hydrochloric acid at $100^{\circ}$ for 20 min. After complete hydrolysis, chromatography on paper showed the presence of cysteic acid and the absence of cystine and histidine.

These results indicate that bromine reacts with histidine residue in bacitracin $A$ and also oxidizes the potential thiol group to a sulphonic acid group. Bromine is known to react with histidine to form an unstable monobromo derivative (Binkley, 1948). The two reactions would therefore account for the absorption of 8 equiv. of bromine, so that 2 equiv. remain unaccounted for.

Attempted fractionation of oxidation product. In a preliminary attempt to discover whether oxidation of the sulphur atom caused bacitracin $A$ to break into two fragments, the peptide was oxidized in concentrated solution ( $11 \mathrm{mg}$. in $0.25 \mathrm{ml}$.) so that a precipitate remained after the excess of bromine had been removed. The washed precipitate $(2 \mathrm{mg}$.) and the material in the supernatant solution (11 mg.) were hydrolysed separately with $6 \mathrm{~N}$-hydrochloric acid at $110^{\circ}$ for $24 \mathrm{hr}$. The two hydrolysates showed chromatograms which were not distinguishable when run in butanol-acetic acid.

\section{Product of hydrogenolysis with Raney nickel}

On hydrogenolysis with Raney nickel the antibacterial activity of bacitracin $A$ fell to about $10 \%$ of its original value. The product reduced no significant amount of ferricyanide either before or after treatment with $0.5 \mathrm{~N}$-hydrochloric acid at $100^{\circ}$, for $20 \mathrm{~min}$. After complete hydrolysis with $6 \mathrm{~N}$-hydrochloric acid it was found to differ in several ways on two-dimensional paper ehromato. grams from the corresponding hydrolysate of

Biochem. 1953, 53 bacitracin $A$. (1) Alanine was present and cystine was absent.' As was expected a cysteine residue had been converted to an alanine residue. (2) Two new substances were present which gave a satisfactory colour with ninhydrin only when the paper was heated more strongly than was required for the development of colour with the amino-acids. One of these substances ran slightly faster than alanine in butanol-acetic acid and slightly faster than valine in phenol-acetic acid. The other ran slightly faster than leucine in both systems. (3) After treatment of the product of hydrogenolysis with FDNB and hydrolysis of the DNP derivative, DNP-alanine was found to be present. The $\alpha$-amino group of the alanine residue in the product of hydrogenolysis was therefore free, unlike the $\alpha$-amino group of the cysteine residue from which it was derived.

\section{Oxidation of hydrogenolysis product with periodate}

Formation of ammonia. The product of hydrogenolysis of crude bacitracin was hydrolysed with $6 \mathrm{~N}$-hydrochloric acid at $110^{\circ}$ for $24 \mathrm{hr}$. and then oxidized with periodate in Conway units in the manner described by Gordon, Martin \& Synge (1943). The oxidation resulted in the formation of 0.64 equiv. of ammonia/1500 $\mathrm{g}$. of peptide hydrochloride. In a control experiment with the material before hydrogenolysis, 0.2 equiv. of ammonia was found.

Formation of an aldehyde. The product of hydrogenolysis of crude bacitracin (150 mg.) was hydro. lysed with $6 \mathrm{~N}$-hydrochloric acid at $110^{\circ}$ and then oxidized with periodate in a flask connected by a tube ending in a sintered-glass filter to a vessel containing a saturated solution of 2:4-dinitrophenylhydrazine in $2 \mathrm{~N}$-hydrochloric acid. The flask was gently warmed and a stream of nitrogen was passed through the apparatus. A yellow 2:4-dinitrophenylhydrazone (7 mg.) was precipitated, m.p. $112-114^{\circ}$ after crystallization from ethanol. This hydrazone has not yet been characterized.

\section{DISCUSSION}

If bacitracin $A$ consisted of an open chain of aminoacids linked only through $\alpha$-amino and $\alpha$-carboxyl groups, and if its amino-acid composition were that suggested in this paper, the minimum stoicheiometric unit of the polypeptide in the free state would have seven ionizable groups. These groups would be: one $\alpha$-carboxyl group, one $\beta$ - and one $\gamma$-(or two $\beta$-)carboxyl groups from aspartic or glutamic acid, one $\alpha$-amino group, one glyoxaline group from histidine, one $\delta$-amino group from ornithine and one e-amino group from lysine. The carboxyl group of the third acidic amino-acid residue could be assumed to be condensed with ammonia to form an asparagine or glutamine fragment. 
In fact, the titration curve of bacitracin $A$ shows the presence of only two carboxyl groups and of only one basic group ionizing in the $\mathrm{pH}$ range 8.5-11.5. Hence one carboxyl group and one $\delta$ - or e-amino group are bound. Further experiments have shown that the amino group that is bound is the $\epsilon$-amino group of lysine, because this group, unlike the $\delta$-amino group of ornithine, does not react with FDNB.

If these results are taken at their face value they indicate that bacitracin $A$ is a cyclic polypeptide in which a carboxyl group is condensed with the $\epsilon$ amino group of a lysine residue. A structure of this type would account for the behaviour of the peptide on titration and on reaction with FDNB. The $\epsilon-$ amino groups of lysine residues are normally thought to be free in proteins, although they have sometimes been found to be unreactive towards FDNB until the protein is denatured (Porter, 1948). The naturally occurring derivative of biotin known as biocytin consists of biotin conjugated with lysine in the $\epsilon$-position (Wright et al. 1951).

A simple closed polypeptide chain is not adequate in itself, however, to describe bacitracin $A$. An addition must be made to it to account for the fact that a thiol group is rapidly liberated when the peptide is treated with hot dilute acid.

The liberation of a thiol group in a naturally occurring polypeptide under relatively mild conditions is of general interest to protein chemistry, because many proteins contain masked thiol groups which are freed when the protein is denatured. How far the unmasking of thiol groups is due to their formation on rupture of specific chemical bonds, or how far it is a consequence of the opening up of the whole protein molecule which makes the groups more accessible to the reagents used for detecting them, does not appear to have been decided (Anson, 1941). With a peptide of relatively low molecular weight, however, the view that a masked thiol group is involved in the formation of a chemical bond would seem to be the more fruitful working hypothesis.

It has been shown that the thiol group liberated in bacitracin $A$ forms part of a cysteine residue, and therefore that the fragment<smiles>CC1CSCC1C(=O)O</smiles>

is present in the original peptide.

The nature of the group to which sulphur is linked through its second valency has proved more difficult to establish. A thiol-ester grouping (-CO.S-), such as that found in acetyl-coenzyme $A$ (Lynen \& Reichert, 1951), does not seem to be present in bacitracin $A$, for the latter develops no red colour on standing with nitroprusside and ammonia, and yields no acid group on mild hydrolysis other than that which is thought to derive from an amide. A simple thiazolidine, in which the nitrogen atom is unacylated, also appears to be excluded, because bacitracin $A$ is not readily oxidized by iodine to a disulphide.

A preliminary investigation of the product of hydrogenolysis of bacitracin $A$ with Raney nickel, however, has provided some evidence about the structure that is present. This product, as would be expected, contains an alanine residue in place of a cysteine residue. But reaction with FDNB shows that the $\alpha$-amino group of the alanine residue, unlike that of the cysteine residue from which it derives, is free. The following change has therefore occurred:

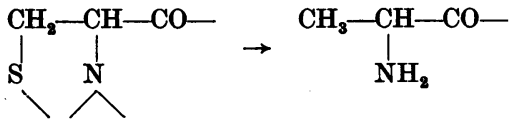

Paper chromatography has shown that hydrolysates of the product of hydrogenolysis contain two substances which are not present in bacitracin $A$ and which react with ninhydrin to form a blue colour. These substances have not yet been identified, but it is possible that one of them is an $\alpha$-amino alcohol, for ammonia and a volatile compound that forms a 2:4-dinitrophenylhydrazone are liberated when the hydrolysate is oxidized with periodate.

An amino alcohol residue might well be formed from an amino aldehyde, or potential amino aldehyde grouping, since treatment with Raney nickel is known to reduce carbonyl compounds (Mozingo, Spencer \& Folkers, 1944). On this view the following changes also occur on hydrogenolysis of bacitracin $A$ :

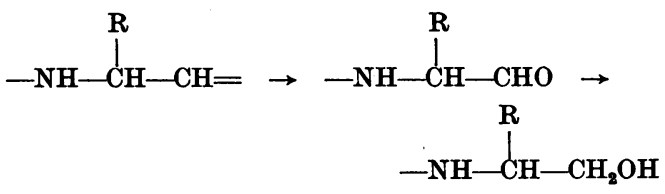

It is tempting to assume that all these changes are initiated by the removal of the sulphur atom. This assumption leads to the idea that a thiazoline ring is present in bacitracin $A$ and is incorporated in the peptide chain in the following manner:<smiles>[R]C(NC)C1=NC(C(=O)O)CS1</smiles>

The possibility that thiazoline rings occur in native proteins, and are the seat of masked thiol groups, has been considered by Linderstrøm-Lang \& Jacobsen (1941), but no direct experimental evi- 
dence for the presence of such rings appears to be available.

In the present case a thiazoline ring would readily account for the liberation of a thiol group on warming with dilute acid. It would also account for the failure of preliminary attempts to find two different peptide fragments when the molecule is broken, at the sulphur atom, by mild treatment with acid or by oxidation with bromine water. Under these conditions a thiazoline ring would give rise to a new peptide bond (Linderstrøm-Lang \& Jacobsen, 1941; Gabriel \& Hirsch, 1896).

Other properties of bacitracin $A$, however, do not appear at first sight to be so readily accounted for by a thiazoline ring.

Thiazolines contain a weakly basic nitrogen atom and there seems to be no room in the titration curve of the peptide for any basic group in addition to the $\alpha$-amino group of leucine, the $\delta$-amino group of ornithine, and the glyoxaline ring of histidine. The nitrogen atom of 2-methyl thiazoline has a pK of 5.4 (Linderstrøm-Lang \& Jacobsen, 1941). The electronegative $\mathrm{CO}$ group of the cysteine residue, which would be attached at the 4-position to any thiazoline present in bacitracin $A$, might be expected to reduce the pK by about 3 units to $\mathrm{pH} 2 \cdot 4$. Thus, primary aliphatic amines have a pK of about 10.5 and the amino group of glycylglycine ester a pK of 7.7 (Neuberger, 1937). To have escaped detection in the titration, under the conditions used, the $\mathrm{pK}$ of a thiazoline nitrogen would need to be less than $\mathbf{1 \cdot 4}$. Whether it is reasonable to postulate such a low value cannot be decided without more knowledge of the detailed structure of the peptide.

Bacitracin $A$ shows an absorption maximum in the ultraviolet region at $254 \mathrm{~m} \mu$., which disappears when the thiol group is liberated by treatment with acid. The sulphur atom may therefore form a part of a structure which absorbs at this wavelength. It is scarcely possible to predict, however, whether a thiazoline derivative incorporated into a peptide chain would be likely to show such an absorption.

On the basis of the information so far available the suggestion that a thiazoline ring is present in bacitracin $A$ can only be regarded as a tentative hypothesis. But it is evident that the structure of the polypeptide presents several features of unusual interest, and that techniques are available which should enable these features to be more clearly delineated.

\section{EXPERIMENTAL}

\section{Amide nitrogen}

Measurement of amide N. Standard Conway units were used (Conway, 1935). The centre compartments were filled with $0.667 \mathrm{ml}$. of $0.007-\mathrm{NHCl}$ containing an indicator consisting of methylene blue and methyl red (Conway, 1935). The sample of bacitracin (1-2 mg.) or bacitracin derivative dissolved in $\mathbf{0 . 2} \mathrm{ml}$. water, was placed in the outer compartment. The amide $\mathrm{N}$ was liberated as volatile base by adding $0.5 \mathrm{ml}$. of saturated potassium metaborate and incubating for $4 \mathrm{hr}$. at $37^{\circ}$. No increase in the amount of volatile base was obtained after hydrolysis under more vigorous conditions.

The excess of acid was titrated against $0.01 \mathrm{~N}-\mathrm{Ba}(\mathrm{OH})_{2}$, using an 'Agla' micrometer syringe obtained from Burroughs Wellcome Ltd., Euston Road, London. During the titration a small magnetically operated stirrer was used to keep the contents of the centre compartment of the cell well mixed. Determinations were made in duplicate.

Lability of amide N. After bacitracin $A$ had been treated under various conditions the following procedure was used to determine whether the amide $\mathrm{N}$ was still intact. The sample of treated bacitracin $A$ was divided into two equal portions which were placed in Conway units as described above. One portion was treated with $0.5 \mathrm{ml}$. saturated potassium metaborate and the other with $0.5 \mathrm{ml}$. saturated $\mathrm{K}_{2} \mathrm{HPO}_{4}(\mathrm{pH} 9 \cdot 0)$. The saturated potassium metaborate hydrolysed the amide group of bacitracin $A$ quantitatively, while the saturated $\mathrm{K}_{2} \mathrm{HPO}_{4}$ (pH 9.0) removed only 5-10\% of the amide $\mathrm{N}$ but liberated over $90 \%$ of the ammonia from a standard $\left(\mathrm{NH}_{4}\right)_{2} \mathrm{SO}_{4}$ solution after $8 \mathrm{hr}$. at $37^{\circ}$.

\section{Paper chromatography of amino-acids}

Samples of bacitracin were hydrolysed and chromatographed on paper as described by Newton \& Abraham (1953).

\section{DNP-bacitracin derivatives}

DNP derivatives were prepared and hydrolysed, and the DNP-amino-acids chromatographed on paper, as described by Newton \& Abraham (1953).

\section{Separation of S-DNP-cysteine and $\delta$-DNP-ornithine by ionophoresis on paper}

Spots of $S$-DNP-cysteine (20 $\mu \mathrm{g}$.) and $\delta$-DNP-ornithine $(20 \mu \mathrm{g}$.) were applied to the centre of a sheet of Whatman no. 1 paper $(50 \times 14 \mathrm{~cm}$.) which had been soaked in $0.02 \mathrm{M}$ sodium borate buffer, $\mathrm{pH} 8 \cdot 8$, and dried between sheets of blotting paper. The buffered paper was then placed between two sheets of plate glass and ionophoresis carried out in the manner described by Kunkel \& Tiselius (1951). A potential of $500 \mathrm{~V}$., giving a current of 3 ma., was applied for $4.5 \mathrm{hr}$. $S$-DNP-Cysteine travelled $13 \mathrm{~cm}$. towards the anode and $\delta$-DNP-ornithine $3 \mathrm{~cm}$. towards the cathode.

\section{Detection and estimation of thiol groups}

(1) Nitroprusside reaction. When testing for free thiol this reaction was carried out by adding one drop of $5 \%(w / v)$ fresh sodium nitroprusside solution and one drop of $35 \%$ (w/w) $\mathrm{NH}_{3}$ to $0.5 \mathrm{ml}$. of the neutral solution to be tested. When testing for disulphide, one drop of $2 \mathrm{~N}-\mathrm{NaCN}$ solution was added before the nitroprusside (Anson, 1941).

(2) Titrations with iodine. These titrations were done by adding a slight excess of $0.0097 \mathrm{~N}-\mathrm{I}_{2}$ in $0.02 \mathrm{~N}-\mathrm{KI}$ to $5-10 \mathrm{mg}$. samples of bacitracin dissolved in $1 \mathrm{ml}$. M-potassium phosphate buffer, pH 6.8, and titrating back immediately with $0.01 \mathrm{~N}$-sodium thiosulphate, using starch as an indicator.

(3) Oxidation by ferricyanide. The oxidation of material by ferricyanide under conditions suitable for estimating free thiol groups was measured in the manner described by Barron (1951). A solution $(0.2 \mathrm{ml}$.) of the sample to be 
tested ( $0.5 \mathrm{mg}$.) was introduced into a colorimeter tube containing $0.25 \mathrm{ml}$. of $1 \mathrm{~m}$-sodium phosphate. The $\mathrm{pH}$ of the phosphate was arranged so that the final $\mathrm{pH}$ of the mixture was $6 \cdot 8$. $0.5 \mathrm{ml}$. of $0.1 \mathrm{M}$-potassium ferricyanide (A.R.) was then added and the mixture kept in the dark for $10 \mathrm{~min}$. After the addition of $1 \mathrm{ml} . \mathrm{N}-\mathrm{H}_{3} \mathrm{PO}_{4}, 0.3 \mathrm{ml}$. of an acid ferric sulphate reagent (Folin \& Malmros, 1929) and 5.25 ml. water, the tube was kept in the dark for $25 \mathrm{~min}$. The amount of ferricyanide resulting from the oxidation, which was proportional to the amount of Prussian blue formed, was then estimated in an E.E.L. photoelectrio colorimeter (Evans Electroselenium Ltd., Harlow, Essex), using a red filter (no. 608). The optical density was related to the amount of ferricyanide by means of a standard curve obtained with volumes of $0.001 \mathrm{~m}$-potassium ferricyanide (A.R.) varying from 0.1 to $0.6 \mathrm{ml}$. By this procedure the amount of free thiol in a sample of cysteine hydrochloride was found to be $95 \%$ of the theoretical value.

\section{Hydrogenolysis with Raney nickel}

Raney nickel was prepared from Ni-Al alloy by the method of Mozingo, Wolf, Harris \& Folkers (1943). About $1 \mathrm{~g}$. of Raney nickel was added to a solution of $100 \mathrm{mg}$. bacitracin $A$ in $20 \mathrm{ml}$. water and the mixture was heated under reflux for $20 \mathrm{~min}$. After removing the catalyst the solution was shaken twice with a solution of 8-hydroxyquinoline in $\mathrm{CHCl}_{3}$ and then four times with $\mathrm{CHCl}_{3}$ alone. It was then freeze-dried, yielding $50 \mathrm{mg}$. of a white powder.

\section{Electrometric titrations}

Titrations were carried out at $20^{\circ}$ in a small Pyrex glass vessel containing a Doran Alkacid glass electrode (made by the Doran Instrument Co. Ltd., Stroud, Glos.) and connected through a bridge of 3.5 $\mathrm{M}-\mathrm{KCl}$ to a calomel half-cell. The $\mathrm{pH}$ was measured directly with a Muirhead $\mathrm{pH}$ meter. $0 \cdot 1 \mathrm{~N}-\mathrm{HCl}$ or $\mathrm{NaOH}$ was delivered from a burette with a fine tip which was placed beneath the surface of the solution to be titrated. The solution was stirred gently by a slow stream of $\mathrm{N}_{2}$. About $10 \mathrm{mg}$. of polypeptide in an initial volume of $2 \mathrm{ml}$. were used in each titration. The blank corrections were estimated from experimental curves.

\section{SUMMARY}

1. Bacitracin $A$ is a polypeptide containing the following amino-acid residues: cysteine, ornithine, lysine, histidine, aspartic acid, glutamic acid, phenylalanine, leucine and isoleucine. The weight of the minimum stoicheiometric unit of bacitracin $A$ hydrochloride is about 1500. The latter contains three molecules of hydrochloric acid and one amide group.

2. Electrometric titration and reaction with 1-fluoro-2:4-dinitrobenzene indicate that the minimum stoicheiometric unit of bacitracin $A$ contains the following ionizable groups: two carboxyls, one $\alpha$-amino group, one histidine glyoxaline, and one $\delta$-amino group of ornithine. The $\epsilon$-amino group of lysine is not free. It is suggested that bacitracin $A$ may be a eyclic polypeptide, in which a carboxyl group is condensed with the e-amino group of lysine.

3. Bacitracin $A$ appears to contain no free thiol group or disulphide, but a thiol group is rapidly liberated when the peptide is treated with hot dilute acid. This group forms part of a cysteine residue. The liberation of the thiol group is accompanied by the hydrolysis of an amide group and by the disappearance of an absorption maximum in ultraviolet light at $254 \mathrm{~m} \mu$.

4. On hydrogenolysis with Raney nickel the cysteine residue of bacitracin $A$ is converted to an alanine residue whose $\alpha$-amino group is free. Hydrolysis of the product of hydrogenolysis yields two new substances which give a blue colour on reaction with ninhydrin. Evidence has been obtained that one of these substances, at least, is an amino alcohol.

7. The possibility that bacitracin $A$ contains a thiazoline ring system is considered in the light of the information so far available.

We wish to thank Mrs A. Giles and Mr Omar Boys for expert technical assistance. One of us (G.G.F.N.) is indebted to the Medical Research Council for a part-time personal grant. The work has been supported by a grant from the Medical Research Council for technical assistance and supply of materials.

\section{REFERENCES}

Anker, H. S., Johnson, B. A., Goldberg, J. \& Meleney, F. L. (1948). J. Bact. 55, 249.

Anson, M. L. (1940). J. gen. Physiol. 23, 247

Anson, M. L. (1941). J. gen. Physiol. 24, 399.

Barron, E. S. G. (1951). Advanc. Enzymol. 11, 201.

Barry, G. T., Gregory, J. D. \& Craig, L. C. (1948). J. biol. Chem. 175, 485.

Binkley, W. W. (1948). J. Amer. chem. Soc. 70, 2010.

Conway, E. J. (1935). Biochem. J. 29, 2755.

Craig, L. C., Gregory, J. D. \& Barry, G. T. (1949). J. clin. Invest. 28, 1014.
Craig, L. C., Hausmann, W. \& Weisiger, J. R. (1952). J. biol. Chem. 199, 865.

Dobbie, H., Kermack, W. O. \& Lees, H. (1951). Biochem. J. 50, v.

Folin, O. \& Malmros, H. (1929). J. biol. Chem. 83, 115.

Gabriel, S. \& Hirsch, C. F. (1896). Ber. dtsch. chem. Ges. 29, 2609.

Gordon, A. H., Martin, A. J. P. \& Synge, R. L. M. (1943). Biochem. J. 37, 538.

Jorpes, E. (1932). Biochem. J. 26, 1507.

Kunkel, H. G. \& Tiselius, A. (1951). J. gen. Physiol. 35, 89. 
Linderstrøm-Lang, K. \& Jacobsen, C. F. (1941). J. biol. Chem. 137, 443.

Lynen, F. \& Reichert, E. (1951). Angew. Chem. 63, 47.

Mozingo, R., Spencer, C. \& Folkers, K. (1944). J. Amer. chem. Soc. 66, 1859.

Mozingo, R., Wolf, D. E., Harris, S. A. \& Folkers, K. (1943). J. Amer. chem. Soc. 65, 1013.

Neuberger, A. (1937). Proc. Roy. Soc. A, 158, 68.

Newton, G. G. F. \& Abraham, E. P. (1950). Biochem. J. 47, 257.
Newton, G. G. F. \& Abraham, E. P. (1953). Biochem. J. 58, 597.

Porter, R. R. (1948). Biochim. biophys. Acta, 2, 105.

Sanger, F. (1945). Biochem. J. 39, 507.

Sharp, V. E., Arriagada, A., Newton, G. G. F. \& Abraham, E. P. (1949). Brit. J. exp. Path. 30, 444.

Woiwod, A. J. (1949). J. gen. Microbiol. 3, 312.

Wright, L. D., Cresson, E. L., Skeggs, H. R., Peck, R. L., Wolf, D. E.,'Wood, T. R., Valiant, J. \& Folkers, K. (1951). Science, 114, 635.

\title{
Anaerobic Reactions of Phospholipins in Brain Suspensions
}

\author{
BY G. H. SLOANE-STANLEY \\ Biochemical Laboratories, Institute of Psychiatry (British Postgraduate Medical Federation, \\ University of London), Maudsley Hospital, London, S.E. 5
}

(Received 25 August 1952)

The metabolism of the brain phospholipins of adult mammals has been found to be slow but significant, in vivo and in vitro (e.g. Perlman, Ruben \& Chaikoff, 1937; Hevesy \& Hahn, 1940; Fishler, Taurog, Perlman \& Chaikoff, 1941; Fries, Schachner \& Chaikoff, 1942; Sperry, 1947), and the known phospholipin-splitting activities of brain extracts are low (King, 1931; Rossi, 1935; Thannhauser \& Reichel, 1936; Goebel \& Seckfort, 1948; SloaneStanley, 1952). Kephalin is apparently turned over faster in vivo than are other phospholipins (Hevesy \& Hahn, 1940; Chargaff, Olsen \& Partington, 1940), although no very active brain enzyme attacking kephalin has yet been described; brain lecithinase might be expected to attack kephalin slowly, as does the similar but more active enzyme in kidney (King, 1931, 1934).

It is now known that brain kephalin is not a single compound, but a mixture of phosphatidylethanolamine (with the classical structure of kephalin), phosphatidylserine and diphosphoinositide (a compound of 'inositol metadiphosphate' with one equivalent each of glycerol and fatty acid); large amounts of sodium, potassium, magnesium and calcium are extracted from brain by lipid solvents as salts of the latter two acidic lipids (Folch, 1942, $1947,1948,1949 a, b)$, and may therefore be combined with them in vivo.

The apparently slow metabolism of the brain phospholipins as a whole might be due to the rapid turnover of one of the individual members of this complex mixture; such a reaction would be of particular interest if it involved one of the acidic kephalins mentioned above, in view of the physiological importance of the cations associated with these substances. Moreover, phosphatidylserine might be decarboxylated to phosphatidylethanolamine, a neutral substance, without any release of lipid phosphorus; such a reaction would not be detected by studies of phosphate turnover in the phospholipins as a whole.

The experiments described below fell, therefore, into two groups. First, the possibility of a rapid decarboxylation of phosphatidylserine by brain preparations in vitro was examined; since no such reaction was in fact detected, these experiments will not be described in detail. Secondly, a search was made for enzymes in brain able to catalyse the rapid hydrolysis of phospholipins; a highly active system, apparently splitting diphosphoinositide, was found. While this reaction was being investigated, two publications from Richter's laboratory appeared, describing the fairly rapid turnover of brain lipid phosphorus in adult mice (Dawson \& Richter, 1950) and a kephalinase reaction in excised brain (Tyrrell, 1950), either or both of which could involve the hydrolysis of diphosphoinositide.

Part of this work has already been published in a preliminary report (Sloane-Stanley, 1951).

\section{EXPERIMENTAL}

All-glass apparatus was used wherever possible. Homogenizers were of the Potter-Elvehjem type (Umbreit, Burris \& Stauffer, 1949), but had smooth pestles without beads sealed on to their bottoms. All $\mathrm{pH}$ measurements were approximate, being made with 'capillators' (British Drug Houses Ltd.).

\section{Preparation of lipids}

Ox-brain kephalin was prepared and fractionated according to Folch (1942), except that fractions I and II were precipitated tugether as the 'inositol phosphatide' (Folch, 1949a); the other lipids used were by-products from 